九州大学学術情報リポジトリ

Kyushu University Institutional Repository

\title{
Controlled-Release Pesticides : 2. Fungicidally Active Water-soluble Polymer
}

Naruse, Hidetoshi

Laboratory of Pesticide Chemistry, Faculty of Agriculture, Kyushu University

Maekawa, Kazuyuki

Laboratory of Pesticide Chemistry, Faculty of Agriculture, Kyushu University

https://doi.org/10.5109/23495

出版情報 : 九州大学大学院農学研究院紀要. 21 (4)，pp. 153-159，1977-07. Kyushu University バージョン：

権利関係 : 


\title{
Controlled-Release Pesticides
}

\section{Fungicidally Active Water-soluble Polymer}

\author{
Hidetoshi Naruse and Kazuyuki Maekawa \\ Laboratory of Pesticide Chemistry, \\ Faculty of Agriculture, Kyushu \\ University 46-02, Fukuoka 812
}

(Received December 25, 1976)

\begin{abstract}
Some water-soluble polymers were prepared as controlled-release fungicides. Copoly(vinyl sodium dithiocarbamate-viny1 isothiocyanate) and poly(ethyleneimine sodium dithiocarbamate) were inhibitory for the growth of Aspergillus niger and Trichoderma viride. Poly(vinyl sodium xanthate) prevented the sporulation of Asp. niger. Poly(5-methylisoxazol-3-yl acrylate) inhibited the mycelial growth of Pythium debaryanum. Decomposition products of poly (ethyleneimine sodium dithiocarbamate) by light was more inhibitory on the growth of Asp. niger than the intact polymer.
\end{abstract}

\section{INTRODUCTION}

Copolymers, to which bioactive groups bind covalently, were recently prepared as an attempt for controlled-release pesticides (Naruse and Maekawa, 1977). The copolymers were found to release some compounds of lower molecular weight by exposure to natural light at a moderate temperature for a considerable time and reveal an antifungal or herbicidal activity. Some of the decomposition products were more fungicidal than the original compound combined with the polymer. For the purpose of further development of these facts, watersoluble polymers combined covalently with a bioactive moiety were synthesized and their antifungal activity was investigated.

\section{MATERIALS AND METHODS}

\section{Chemical modification of some synthetic polymers}

\section{1) Copoly (vinyl sodium dithiocarbamate-vinyl isothiocyanate) $(I)$}

By means of Hofmann degradation of poly(acrylamide) $\left(n=10^{4}\right.$, Katayama Kagaku commercial product), poly(vinylamine) (II) with $83 \%$ of primary amine content was obtained (Sugiura et al., 1969). Ultraviolet absorption spectrum of this compound (II) as hydrochloride salt was shown in Fig. 1. Anal. Found $(\%): \mathrm{N}, 16.33 . \eta_{s p} / c\left(0.5 \%\right.$ aq. soln., $\left.20^{\circ} \mathrm{C}\right)=2.7222 . \quad \operatorname{IR} \nu_{\max }^{\mathrm{KBr}}\left(\mathrm{cm}^{-1}\right): 3400-3200$ $(-\mathrm{NH}-,-\mathrm{COOH}), 2900\left(-\mathrm{CH}_{2}{ }^{-}\right), 2800-2000\left(-\mathrm{NH}_{3}^{+} \mathrm{Cl}^{-}\right), 1700-1500(-\mathrm{CONH}-,-\mathrm{COOH})$. Empirical formula : $\left(\mathrm{C}_{14} \mathrm{H}_{33} \mathrm{~N}_{5} \mathrm{O}_{3} \mathrm{Cl}_{4}\right)_{n=715 .}$.

Ten $\mathrm{ml}$ of $15 \%$ aqueous sodium hydroxide solution was added to $10 \mathrm{ml}$ of $1 \%$ poly(vinylamine hydrochloride), then mixed with $2 \mathrm{ml}$ of carbon disulfide. 


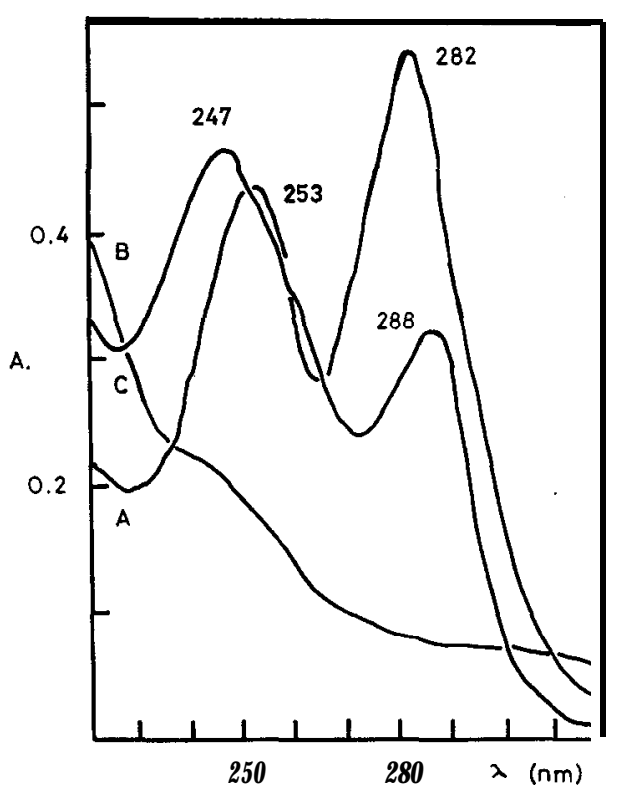

Fig. 1. UV spectra of copoly(vinyl sodium dithiocarbamate-viny 1 isothiocyanate) (A), poly(vinylamine) (B), and sodium ethyldithiocarbamate (C).

The mixture was stirred for 5 hours at $40^{\circ} \mathrm{C}$. The red reaction mixture was dialyzed against water, then was concentrated to $50 \mathrm{ml}$ in vacuo. The residue was poured into $500 \mathrm{ml}$ of tetrahydrofuran to give a yellow precipitate which was filtered, washed well with methanol and ether, then dried under reduced pressure. One-fourth gram of copoly(vinyl sodium dithiocarbamate-viny 1 isothiocyanate) was obtained (Carpov et al., 1971; Hoff and Blok, 1973). Anal. Found $(\%): \mathrm{C}, 38.41 ; \mathrm{H}, 5.78 ; \mathrm{N}, 16.18 . \eta_{s p} / c\left(0.5 \%\right.$ aq. soln., $\left.20^{\circ} \mathrm{C}\right)=0.7327$. $\mathrm{UV} \lambda_{\max }^{\mathrm{H}_{2} \mathrm{O}}(\mathrm{nm}): 282(-\mathrm{NHC}=\mathrm{S}), 247(-\mathrm{CSSNa})\left(\right.$ Fig. 1). IR $\nu_{\max }^{\mathrm{KBr}}\left(\mathrm{cm}^{-1}\right): 3400-3000$ $(-\mathrm{NH}-,-\mathrm{OH}), 2900,1430\left(-\mathrm{CH}_{2}-\right), 2100 \quad(-\mathrm{N}=\mathrm{C}=\mathrm{S}), 1700-1500$ (-CONH-, $-\mathrm{COOH}$, $\left.-\mathrm{NHC}^{\prime}=\mathrm{S}\right), 1250\left(-{ }^{\mathrm{C}} \mathrm{H}-\mathrm{NH}-\right), 1120(\mathrm{C}=\mathrm{S})$ (Fig. 2).

The aqueous solution of the copolymer produced water-insoluble precipitates by heating or on standing long at room temperature. The dithiocarbamoyl content determined by UV spectrometry was $25 \%$ as sodium diethyldithiocarbamate.

2) Poly (ethyleneimine sodium dithiocarbamate) (III)

Poly(ethyleneimine sodium dithiocarbamate) was prepared from poly(ethyleneimine) (Tokyokasei Organic Chemicals) (IV), sodium hydroxide, and carbon disulfide (Okawara et al., 1966). The dithiocarbamoyl content determined was 14.3 mole $\%$ (Clark et al., 1951). $\eta_{s p} / c\left(0.5 \%\right.$ aq. soln., $\left.20^{\circ} \mathrm{C}\right)=0.3830$. Anal. Found $(\%): \mathrm{C}, 26.40 ; \mathrm{H}, 5.21 ; \mathrm{N}, 10.44 . \mathrm{UV}_{\max }^{\mathrm{H}_{2} \mathrm{O}}(\mathrm{nm}): 292\left(=\mathrm{N}-\mathrm{C}^{\prime}=\mathrm{S}\right), 257(-\mathrm{CSSNa})$. $\mathrm{IR} \nu_{\max }^{\mathrm{KBr}}\left(\mathrm{cm}^{-1}\right): 3400-3000(-\mathrm{NH}-$, hydrate $-\mathrm{OH}), 2900\left(-\mathrm{CH}_{2}^{-}\right), 1630$ (hydrate -OH), $1460(=\mathrm{N}-\stackrel{\dot{C}}{\mathrm{C}}=\mathrm{S}), 1120(\mathrm{C}=\mathrm{S})$. 
The product in dimethylformamide or aqueous solution was decomposed by natural light at room temperature to release sulfur-containing compounds and to become alkaline.

3) Poly (vinyl sodium xanthate) (V)

A mixture of $38 \mathrm{~g}$ of carbon disulfide, $300 \mathrm{ml}$ of aqueous solution of $7 \%$ poly(vinyl alcohol) ( $\mathrm{n}=500$, Katayama Kagaku Chemicals), and $100 \mathrm{ml}$ of $20 \%$ sodium hydroxide solution was agitated for 10 hours at $30^{\circ} \mathrm{C}$. After the reaction was over, the lower layer, unreacted carbon disulfide, was separated off. The aqueous layer obtained was dialyzed against water and lyophilized to give $8.2 \mathrm{~g}$ of a hygroscopic yellowish-green powder (Pramanik and Choudhury, 1970). The detection of sulfur by Lassaigne's test was positive. Anal. Found ( $\%$ ) : C, 46.83; $\mathrm{H}$, 7.87. Empirical formula: $\left(\mathrm{C}_{28} \mathrm{H}_{55} \mathrm{O}_{14} \mathrm{~S}_{2} \mathrm{Na}\right)_{\mathrm{n}=36}$. $\mathrm{UV}_{\text {max }}^{\mathrm{H}_{2} \mathrm{O}}(\mathrm{nm}): 302(-\mathrm{CSSNa})$. $\mathrm{IR} \nu_{\max }^{\mathrm{KBr}}\left(\mathrm{cm}^{-1}\right): 3300(-\mathrm{OH}), 2900\left(-\mathrm{CH}_{2}-\right), 1640(-\mathrm{OCOCH}),, 1140-1010(-\mathrm{CSSNa})$. The xanthate content by UV spectrometry : $18.6 \%$.

4) Poly(5-methylisoxazol-3-yl acrylate) (VZ)

Acryloyl chloride was synthesized from acrylic acid and benzoyl chloride (Stempel et al., 1950). Four and a half grams of acryloyl chloride were polymerized by UV-irradiation from high pressure mercury lamp under dry nitrogen gas for 5 hours at room temperature. Tetrahydrofuran-soluble poly (acryloyl chloride) with $80 \%$ of acid chloride content was obtained in a good yield (Vrancken and Smetz, 1954; Linoli et al., 1970).

Four grams of 3-hydroxy-5-methylisoxazole (Tomita et al., 1973) and $5.5 \mathrm{~g}$ of triethylamine dissolved in $50 \mathrm{ml}$ dry tetrahydrofuran were added to $100 \mathrm{ml}$ of $4 \%$ poly(acryloyl chloride) tetrahydrofuran solution. The mixture was stirred for 22 hours at $25^{\circ} \mathrm{C}$, then allowed to stand until two layers appeared. The lower layer treated with $\mathbf{2 0} \mathrm{ml}$ of $\mathbf{2 0} \%$ aqueous solution of triethylamine at room temperature divided into two layers on standing. The separated lower layer was poured into chloroform to give deposits whose solution of methanol was poured into $2 l$ of ether to give precipitates which were filtered, washed with chloroform and dried in vacuo. Yield of the crude product was $0.9 \mathrm{~g}$. An aqueous solution of the crude product was dialyzed against water and lyophilyzed to give a hygroscopic white powder. Yield $0.3 \mathrm{~g} . \eta_{s p} / c\left(1 \%\right.$ aq. soln., $\left.20^{\circ} \mathrm{C}\right)$ $=5.5531$. Anal. Found (\%) : C, 49.43; H, 6.46; N, 2.18. Empirical formula: $\left(\mathrm{C}_{28} \mathrm{H}_{35} \mathrm{NO}_{17}\right)_{\mathrm{R}}$. IR $\nu_{\max }^{\mathrm{KBr}}\left(\mathrm{cm}^{-1}\right): 3400-3300(-\mathrm{COOH}), 2900\left(-\mathrm{CH}_{2}-\right), 2800-2400$ (isoxazole ring), 1720 (-COOR), $1710(-\mathrm{COOH}), 1690-1610 \quad(-\mathrm{CH}=\dot{\mathrm{C}}-, \mathrm{C}=\mathrm{N}), 1260$ (-COOR), 1160 (-COOK) (Fig. 2).

The molar ratio of 5-methylisoxazol-3-yl acrylate and acrylic acid in the product was supposed to be $1: 7$ from analysis.

5) Poly (5-vinyl 2-amino-1,3,4-thiadiazole) (VZZ)

Nine grams of thiosemicarbazide were added drop by drop to $3.5 \mathrm{~g}$ of poly. (acrylic acid) (Wako Pure Chemicals) in $186 \mathrm{~g}$ of $98 \%$ sulfuric acid. The homogeneous solution was further stirred for 7 hours at $80-90^{\circ} \mathrm{C}$, and then the reaction mixture was cooled to room temperature (Elderfield and Sherman, 1961; Kurono, 1974). Insoluble parts in the reaction mixture was removed by a glassfilter. The filtrate was added carefully to $1 l$ of cold ether with stirring, to 


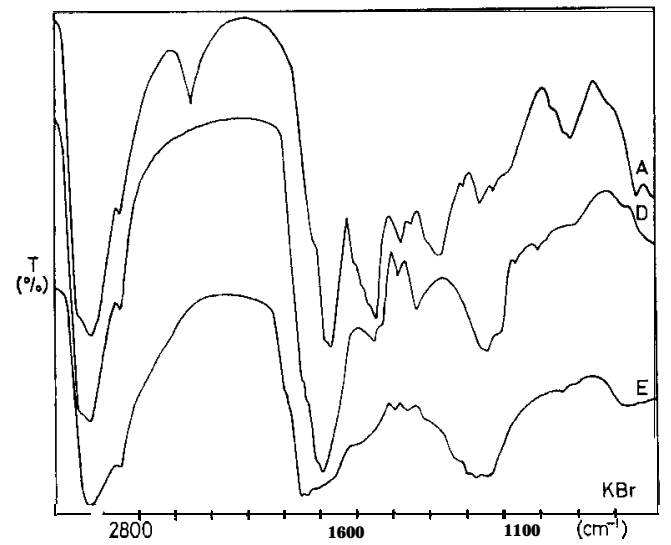

Fig. 2. IR spectra of copoly(vinyl sodium dithiocarhamate-viny 1 isothiocyanate) (A), copoly (5-vinyl 2-amino-1,3,4-thiadiazole-potassium a c r y late) (D), and copoly(5-methylisoxazol-3-yl acrylate-acrylic acid (E).

obtain yellow precipitates. The precipitates were neutralized with potassium carbonate solution, then filtered, and washed thoroughly with acetone. An aqueous solution of the product was dialyzed against water and lyophilyzed to yield $2.2 \mathrm{~g}$ of light brown powder. The detection of sulfur by Lassaigne's test was positive. $\eta_{s p} / c\left(1 \%\right.$ aq. soln., $\left.20^{\circ} \mathrm{C}\right)=0.1855$. Anal. Found $(\%): \mathrm{C}, 42.50$; $\mathrm{H}$, 5.42: N, 17.40; Ash, (+). Empirical formula : $\left(\mathrm{C}_{9} \mathrm{H}_{12} \mathrm{O}_{2} \mathrm{SK}_{2}\right)_{\mathrm{n}}$. UV $\lambda_{\max }^{\mathrm{NN} \text { Nan }}$ $(\mathrm{nm}): 251$ (2-amino-1,3,4-thiadiazole ring). $\operatorname{IR} \nu_{\max }^{\mathrm{KBr}}\left(\mathrm{cm}^{-1}\right): 3400(-\mathrm{NH}-), 3300$ (-COOK), $2900\left(-\mathrm{CH}_{2}-\right)$, 1720-1600 (-COOK, C=N) (Fig. 2).

The thiadiazole content estimated by UV spectrometry was 25 mole $\%$ as 2-amino-1,3,4-thiadiazole.

\section{Fungicidal test}

An antifungal activity of the intact or decomposed polymer was evaluated by paper disc method using Toyokagaku's qualitative filter paper with $6 \mathrm{~mm}$ diameter. Aspergillus niger, Trichoderma viride Pers. ex. Fr. (IFO 5720) and Pythium debaryanum Hesse (IFO 5919) were incubated at $28^{\circ} \mathrm{C}$ under a moderate humidity. The culture medium was $3 \%$ Czapek-agar for Asp. niger, and $3 \%$ potato-sucrose-agar for $\mathbf{T}$. viride and $\mathbf{P}$. debaryanum. The fungicidal activity was defined as rate of sporulation, extent of inhibiting zone and persistence. The inhibiting zone was measured at 5 to 11 days after inoculation (Yamamoto, 1960; Sugawara and Koyama, 1971; Reddish, 1957; Golden and Oster, 1947). The results were shown in Table 1.

\section{RESULTS AND DISCUSSION}

Copoly(vinyl sodium dithiocarbamate-viny1 isothiocyanate) obtained by the dithiocarbamoylation of poly(vinylamine) had an inhibitory effect on the mycelial growth of $\mathbf{A s p}$. niger and T. viride. The active substances were thought 
Table 1. Fungicidal activity of synthetic polymers.*

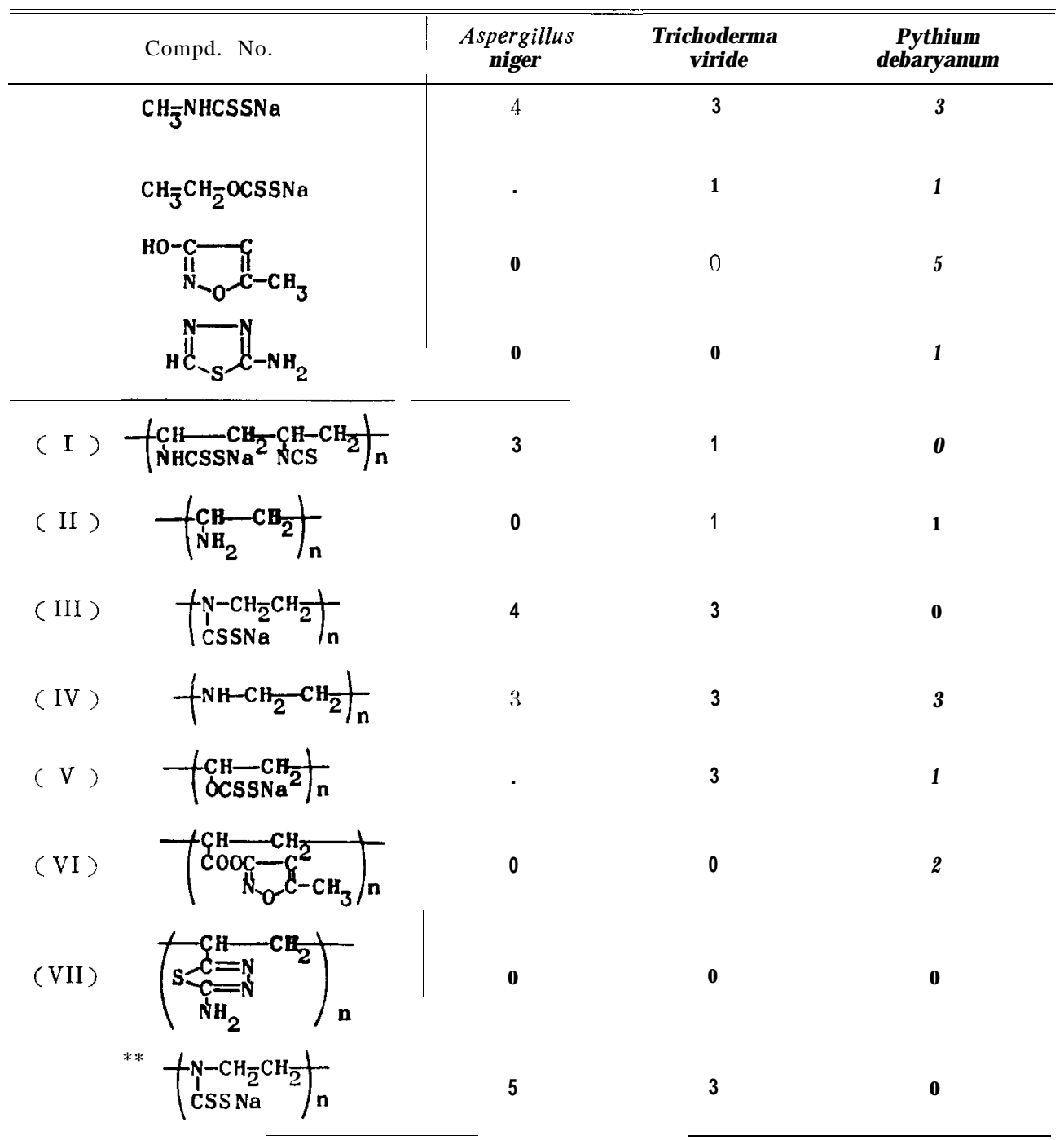

5: Zone of inhibition was more than $4 \mathrm{~cm}$.

4: Zone of inhibition was more than $2 \mathrm{~cm}$.

3 : Zone of inhibition was less than $2 \mathrm{~cm}$.

2 : Organism failed to grow on disc.

1 : Slight growth of organism on disc.

- : No sporulation.

0 : No inhibition.

* : $\mathbf{0 . 5 \%}$ aqueous solution.

**: Compound decomposed by natural light at room temperature. 
to be sulfur, carbon disulfide, hydrogen sulfide, carbonyl sulfide, and sodium hydrosulfide released from the dithiocarbamate and isothiocyanate groups by hydrolysis or decomposition by light.

Asp. niger and T. viride were inhibited to grow by poly(ethyleneimine). Poly(ethyleneimine sodium dithiocarbamate) inhibited the growth of Asp. niger stronger than poly (ethyleneimine) did, and revealed the antifungal activity on Asp. niger in doors for about 8 months at 70-80 \% humidity. The aqueous solution of yellow poly(ethyleneimine sodium dithiocarbamate) was decomposed by natural light at room temperature. The mixture of decomposition products exhibited a stronger inhibitory activity on the growth of Asp. niger than intact poly(ethyleneimine sodium dithiocarbamatr) and sodium methyldithiocarbamate.

The sporulation of Asp. niger was influenced by poly(vinyl sodium xanthate) with a less fungicidal activity than that of sodium ethylxanthate.

A viscous aqueous solution of poly(5-methylisoxazol-3-yl acrylate) was harmful for the growth of $\mathbf{P}$. debaryanum on the disc paper. This polymer can release 3-hydroxy-5-methylisoxazole by the effect of neighbouring carboxyl group (Sakurada, 1968) to the isoxazole group, as shown in Scheme 1.

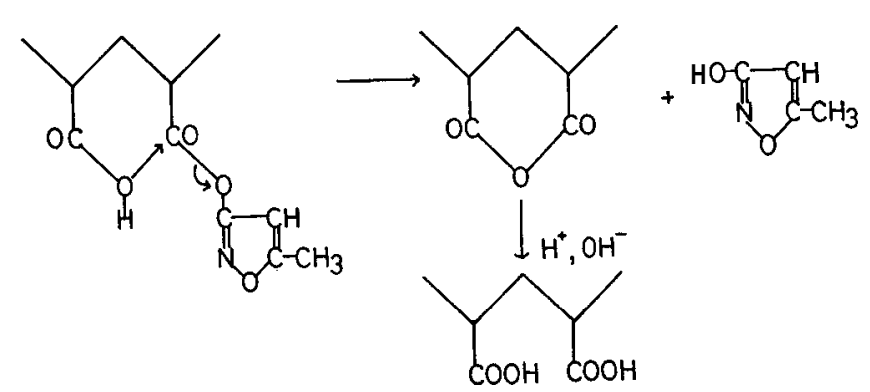

Scheme 1. Release of 3-hydroxy-5-methylisoxazole by hydrolysis.

It was evident that hydrolyzing velocity (Smets and van Humbeeck, 1963) of the ester was in concert with the neighbouring effect of carboxyl group at the release of pesticidal alcoholic moiety from the copolymer.

Poly(5-vinyl 2-amino-1,3,4-thiadiazole) was not effective on the growth of the three species of fungi.

It is concluded from these experiments that some water-soluble polymers which can be decomposed by hydrolysis or light to release antifungal substances are useful for the control of fungi.

\section{ACKNOWLEDGEMENT}

We are grateful to Dr. Eiji Taniguchi for helpful suggestions. 


\section{REFERENCES}

Carpov, A., S. Mavim, 0. Petreus and M. Dima 1971 Reaction of vinyl polymer which contains amino group with organic sulfur compound 1. Bul. Inst. Politeh. Zasi, 16: 401-410

Clark, D. G., H. Brauw, E. L. Stanley and W. F. Hester 1951 Determination of dithiocarbamates. Anal. Chem., 23: 1842-1846

Elderfield, R. C. and W. R. Sherman 1961 Heterocyclic Compounds. Vol. 7, John Wiley and Sons, New York, pp. 587-595

Golden, M. J. and K. A. Oster 1947 Evaluation of a fungicidal laboratory test method. $J$. Am. Pharm. Assoc., 36: 350-362

Hoff, S. and A. P. Blok 1973 Synthesis of 1-alkyl derivatives of isothiocyanatrs, dithiocarbamates, and thiourea. Rec. Trav. Chim., 93: 78-80

Kurono, H. 1974 Sakkinzai no doko. Chemical Industry, 25: 1354-1359

Linoli, G., E. Mannucci and C. Bergonizi 1970 Natural and synthetic polymers as reagents. J. Polymer Sci., A-l, 8: 1481-1491

Naruse, H. and K. Maekawa 1977 Controlled-release pesticides 1. Dithiocarbamate derivatives. J.Fac. Agr., Kyushu Univ., 21: 107-116

Okawara, M., M. Ori, T. Nakai and E. Imoto 1966 Dithiocarbamate-ki o fukumu poly(ethyleneimine) no gosei to hanno. Kogyo Kagaku Zasshi, 69: 766-771

Pramanik, A. G. and P. K. Choudhury 1970 Polyelectrolyte behavior and macromolecular properties of sodium amylopectin xanthate in dilute solution. J. Polymer Sci., A-1, 8: $1713-1724$

Reddish, G. F. 1937 Fungistatic and Fungicial Test Methods, Antiseptics, Disinfectants, Fungicides, and Chemical and Physical Sterization. 2nd ed., Lea and Febiger, Philadelphia, pp. 141-151

Sakurada, I. 1968 Kobunshi kagakuhanno no kiso. Kobunshi, 17:21-26; 207-213

Smetz, G. and W. van Humbeeck 1963 Rection kinetics and tacticity of macromolecules II. Acrylic acid copolymer. J. Polymer Sci., A-1, 1: 1227-1238

Stempel, G. H., R. P. Cross and R. P. Mariella 1950 The preparation of acryloyl chloride. J. Am. Chem. Soc., 72: 2299-2300

Sugiura, M., M. Ochi, Y. Tani and Y. Nagai 1969 Poly(acrylamide) no Hofmann bunkai. Kogyo Kagaku Zasshi, 72: 1926-1928

Sugawara, H. and K. Koyama 1971 Noyaku no Seibutsu Kenteiho. Nankodo, Tokyo, pp. 1-44

Tomita, K., Y. Takaki and R. Ishizuka 1973 Hymexazole, a new plant protecting agent. Ann. Sankyo Res. Lab., 25: 1-18

Vrancken, M. and G. Smetz 1954 Polymers and groups interactions. J. Polymer Sci., 14: $521-534$

Yamamoto, R. 1960 Shinnoyaku Kenkyuho. Nankodo, Tokyo, pp. 341-377 